\title{
Exogenous Application of Methyl Jasmonate and Salicylic Acid Mitigates Drought-Induced Oxidative Damages in French Bean (Phaseolus vulgaris L.)
}

\author{
Mohammed Mohi-Ud-Din 1,*(1), Dipa Talukder ${ }^{1}$, Motiar Rohman ${ }^{2}$, Jalal Uddin Ahmed ${ }^{1}$, \\ S. V. Krishna Jagadish ${ }^{3}$, Tofazzal Islam ${ }^{4, *}$ and Mirza Hasanuzzaman ${ }^{5, *}$ (D) \\ 1 Department of Crop Botany, Bangabandhu Sheikh Mujibur Rahman Agricultural University, \\ Gazipur 1706, Bangladesh; medipaone@gmail.com (D.T.); jahmed06@bsmrau.edu.bd (J.U.A.) \\ 2 Plant Breeding Division, Bangladesh Agricultural Research Institute, Gazipur 1701, Bangladesh; \\ mrahman@bari.gov.bd \\ 3 Department of Agronomy, Kansas State University, Manhattan, KS 66506, USA; kjagadish@ksu.edu \\ 4 Institute of Biotechnology and Genetic Engineering (IBGE), Bangabandhu Sheikh Mujibur Rahman \\ Agricultural University, Gazipur 1706, Bangladesh \\ 5 Department of Agronomy, Faculty of Agriculture, Sher-e-Bangla Agricultural University, \\ Dhaka 1207, Bangladesh \\ * Correspondence: mmu074@bsmrau.edu.bd (M.M.-U.-D.); tofazzalislam@bsmrau.edu.bd (T.I.); \\ mhzsauag@yahoo.com (M.H.)
}

\section{check for} updates

Citation: Mohi-Ud-Din, M.; Talukder, D.; Rohman, M.; Ahmed, J.U.; Jagadish, S.V.K.; Islam, T.; Hasanuzzaman, M. Exogenous Application of Methyl Jasmonate and Salicylic Acid Mitigates DroughtInduced Oxidative Damages in French Bean (Phaseolus vulgaris L.). Plants 2021, 10, 2066. https:// doi.org/10.3390/plants10102066

Academic Editor: Fermin Morales

Received: 27 August 2021

Accepted: 27 September 2021

Published: 30 September 2021

Publisher's Note: MDPI stays neutral with regard to jurisdictional claims in published maps and institutional affiliations.

Copyright: (c) 2021 by the authors. Licensee MDPI, Basel, Switzerland. This article is an open access article distributed under the terms and conditions of the Creative Commons Attribution (CC BY) license (https:// creativecommons.org/licenses/by/ $4.0 /)$.

\begin{abstract}
Drought stress impairs the normal growth and development of plants through various mechanisms including the induction of cellular oxidative stresses. The aim of this study was to evaluate the effect of the exogenous application of methyl jasmonate (MeJA) and salicylic acid (SA) on the growth, physiology, and antioxidant defense system of drought-stressed French bean plants. Application of MeJA $(20 \mu \mathrm{M})$ or SA $(2 \mathrm{mM})$ alone caused modest reductions in the harmful effects of drought. However, combined application substantially enhanced drought tolerance by improving the physiological activities and antioxidant defense system. The drought-induced generation of $\mathrm{O}_{2}{ }^{\bullet-}$ and $\mathrm{H}_{2} \mathrm{O}_{2}$, the MDA content, and the LOX activity were significantly lower in leaves when seeds or leaves were pre-treated with a combination of MeJA $(10 \mu \mathrm{M})$ and SA $(1 \mathrm{mM})$ than with either hormone alone. The combined application of MeJA and SA to drought-stressed plants also significantly increased the activities of the major antioxidant enzymes superoxide dismutase, catalase, peroxidase, glutathione peroxidase, and glutathione-S-transferase as well as the enzymes of the ascorbate-glutathione cycle. Taken together, our results suggest that seed or foliar application of a combination of MeJA and SA restore growth and normal physiological processes by triggering the antioxidant defense system in drought-stressed plants.
\end{abstract}

Keywords: abiotic stress; antioxidant defense; phytohormones; photosynthesis; pulse crop; water deficit

\section{Introduction}

French bean (Phaseolus vulgaris L.) is one of the world's most widely cultivated bean species [1]. For example, in Central and South America it accounts for $90 \%$ of total bean production [2]. It is a dual-purpose crop that is grown as pulse (grain) and consumed in the immature stage as a tender vegetable [3]. However, bean cultivation in approximately $60 \%$ of the regions around the world is affected by drought stress during different periods of crop growth $[1,4]$. Drought stress decreases plant growth and development by changing plant morphology and triggering variations in a suite of key physiological and biochemical processes [5]. Drought stress is known to increase leaf proline content and decrease leaf chlorophyll content, relative water content, stomatal conductance, cell membrane stability, and maximal efficiency of photosystem II by interrupting the electron transport 
chain and chloroplast integrity [6]. Drought stress during the bean flowering period decreases the number of pods per plant and the number of seeds per pod [7], thereby reducing productivity. Frequent, longer, and more severe droughts, accompanied by erratic rainfall, are expected in the 21st century across many regions of the world [8,9], including Bangladesh [10], due to the fact of climate change. This predicted increase in episodes of drought stress will constrain crop cultivation and productivity in the future.

Drought-stressed plants experience oxidative damage due to the generation of reactive oxygen species (ROS; singlet oxygen $\left[{ }^{1} \mathrm{O}_{2}\right]$, superoxide radical $\left[\mathrm{O}_{2}{ }^{\bullet-}\right]$, hydrogen peroxide $\left[\mathrm{H}_{2} \mathrm{O}_{2}\right]$, and hydroxyl radical $\left.\left[{ }^{\circ} \mathrm{OH}\right]\right)$. The ROS-induced damage to biomolecules is one of the major factors that limit plant growth under drought stress [11]. Increased ROS accumulation severely damages cell membrane integrity by accelerating lipid peroxidation [12,13], protein degradation, and nucleic acid damage [14]. Plants can mitigate the toxicity of ROS by activating a dynamic antioxidative defense system comprised of both non-enzymatic and enzymatic constituents $[15,16]$. The enzymatic components of this antioxidant defense mechanism contain superoxide dismutase (SOD), four enzymes of the ascorbate-glutathione cycle (i.e., ascorbate peroxidase (APX), monodehydroascorbate reductase (MDHAR), dehydroascorbate reductase (DHAR), and glutathione reductase (GR)), catalase (CAT), glutathione peroxidase (GPX), and glutathione $s$-transferase (GST) $[15,17]$. The non-enzymatic antioxidants are ascorbate (AsA), glutathione (GSH), tocopherol, flavanones, carotenoids, and anthocyanins, among others [16].

Exogenous application of cellular protectants, such as plant hormones, signaling molecules, and trace elements, is a popular approach in research aimed at enhancing abiotic stress tolerance [18-20]. For instance, methyl jasmonate (MeJA) and salicylic acid (SA) are the regulatory phytohormones that play a pivotal role in plant signaling responses to environmental cues through the orchestration of a myriad of defensive mechanisms [20-23]. The exogenous application of these two hormones together to mustard [18,24], grasses [25], jatropha [22], Verbascum [26], and maize [27] has been shown to protect plants against abiotic stresses, including drought, by regulating important physiological processes ranging from photosynthesis to nitrogen and proline metabolism and by activating the antioxidant defense system. Previous studies on wheat [28], maize [27], sweet potato [29], and Eureka lemon [30] have suggested that treatment with 5-20 $\mu \mathrm{M}$ MeJA and/or 0.5-2 mM SA effectively enhances the defense signaling routes to mitigate damage due to the abiotic stresses.

A number of reports have confirmed the protective role of MeJA and SA under abiotic stress conditions; however, few investigations have examined the combined application of these plant signaling molecules for mitigation of oxidative damage in plants under stressful conditions. Moreover, to the best of our knowledge, no studies have aimed to elucidate the impact of exogenous MeJA and SA, independently or in combination, on the amelioration of drought-induced oxidative stress in French bean. Recently, Tayyab et al. [27] demonstrated that the combined application of MeJA and SA significantly improved drought tolerance in maize seedlings. Therefore, the goal of this study was to examine how drought-stressed French bean plants respond to exogenous MeJA and SA, applied both separately and in combination, as seed and foliar pre-treatments. The findings from this study provide new mechanistic insights into the coordinated actions of MeJA and SA on the antioxidant defense system in French beans to enhance tolerance against drought-induced oxidative stress. The specific objectives of the study were (i) to determine the effects of exogenous application of MeJA and SA, separately and in combination, on the morpho-physiological traits of French beans and (ii) to evaluate the role of exogenous MeJA and SA and their combined application on the antioxidant defense system of French bean plants exposed to drought stress conditions.

\section{Materials and Methods}

\subsection{Plant Material, Experimental Conditions, and Treatments}

A popular, high yielding, and widely cultivated French bean variety, BARI Jharsheem1 , was used as the experimental material. Seeds were collected from the Vegetable Divi- 
sion, Horticulture Research Center, Bangladesh Agricultural Research Institute, Gazipur, Bangladesh. The experiment was carried out in a dry and cool environment (Table S1).

Methyl jasmonate (CAS \#39924-52-2) and salicylic acid (CAS \#69-72-7) were purchased from Sigma-Aldrich Chemie GmbH, Germany. Seeds were surface-sterilized with 1\% $(v / v)$ sodium hypochlorite for $10 \mathrm{~min}$ and rinsed thoroughly 3 times with sterile distilled water and then soaked in solutions of $20 \mu \mathrm{M}$ MeJA and $2 \mathrm{mM} \mathrm{SA}$ for $18 \mathrm{~h}$ prior to sowing, while seeds for the combined application were soaked in an equal volume mixture of $10 \mu \mathrm{M}$ MeJA and $1 \mathrm{mM} \mathrm{SA} \mathrm{[27].} \mathrm{Seeds} \mathrm{for} \mathrm{the} \mathrm{control} \mathrm{and} \mathrm{drought} \mathrm{groups} \mathrm{were} \mathrm{soaked} \mathrm{in} \mathrm{sterile}$ water. Seeds were then sown in pots $(18 \mathrm{~cm}$ in diameter $\times 23 \mathrm{~cm}$ in height) containing $13 \mathrm{~kg}$ of silt loam soil (sand $26 \%$, silt $50 \%$, and clay $24 \%$ ), maintained at a full pot capacity of $30.6 \%$ volumetric soil water content. The soil was fertilized properly as recommended by Ahmmed et al. [31]. Ten healthy seeds were sown per pot, maintaining uniform spacing in each pot. Seven days after germination, seedlings were thinned to retain five uniform and healthy seedlings in each pot. Fifteen days after germination, the seedlings, which were previously soaked in the hormones, were again treated with MeJA $(20 \mu \mathrm{M})$, SA $(2 \mathrm{mM})$, and combined $(10 \mu \mathrm{M}$ MeJA $+1 \mathrm{mM} \mathrm{SA})$ solutions as foliar spray. Another set of plants were sprayed with distilled water. Drought stress was imposed a day after the foliar spray by stopping irrigation until the end of the experiment, while the control pots were well watered. The experiment was a completely randomized design (CRD) with five treatments (control, drought (D), drought-stressed plants treated with methyl jasmonate (D + MeJA), salicylic acid (D + SA), and their combination (D + MeJA + SA)) with four replications.

\subsection{Pot Capacity and Water Content of the Experimental Soil}

The pot capacity of the soil used was measured prior to the start of the experiment gravimetrically using the procedure of Ogbaga et al. [32]. Briefly, pots of completely water-saturated soil were weighed and then dried to a constant weight at $105{ }^{\circ} \mathrm{C}$. The differences between the weights of the water-saturated and oven-dried soils were used to determine the amount of water required to bring the pots to pot capacity, and volumetric water content (\%) was determined accordingly. In addition, the water content (\%) of the pot soils (at a $15 \mathrm{~cm}$ depth) was monitored daily using a digital soil moisture meter (PMS-714, Lutron Electronic Enterprise Co., Ltd., Taiwan, China).

\subsection{Growth Parameters}

At harvest (25 days after foliar application), root length (RL), shoot length (SL), root dry weight (RDW), shoot dry weight (SDW), leaf dry weight (LDW), and total dry weight (TDW) were calculated from 5 plants in each replication. Root and shoot length were determined from the root-shoot junction to the tip of the longest root and shoot, respectively, using a meter scale. Dry weights were weighed after drying the plant samples at $80^{\circ} \mathrm{C}$ until a stable weight was reached.

\subsection{Physiological Parameters}

\subsubsection{Leaf Chlorophyll and Pigment Content}

At harvest, three 3rd fully expanded leaves from each replicate were used to estimate leaf SPAD value (chlorophyll index) and pigment contents. SPAD value was recorded just before the final harvest with a Chlorophyll Meter (Model: SPAD-502, Minolta Co., Ltd., Tokyo, Japan). Then, the leaves were harvested into Ziplock polybags and brought to the laboratory for pigment extraction. Leaf pigments were extracted in $80 \%(v / v)$ acetone and absorbance of the supernatant was determined with a UV-visible spectrophotometer (GENESYS 10S UV-VIS, Thermo Fisher Scientific, Waltham, MA, USA) at 663, 645, and $470 \mathrm{~nm}$ for $\mathrm{Chl} \mathrm{a}, \mathrm{Chl} \mathrm{b}$, and carotenoid content, respectively, and calculated according to Arnon [33]. 


\subsubsection{Canopy Temperature Depression}

Canopy temperature was measured on alternate days by a hand-held infrared thermometer (Model- MT4, HTC Instruments, Taipei, Taiwan, China; distance-spot ratio, 12:1). An angle of approximately $30^{\circ}$ to the horizontal line and a distance of $30 \mathrm{~cm}$ from the 3rd fully opened leaf surface was maintained during measurement of the canopy temperature. Canopy temperature depression (CTD) was determined using the procedure of Fischer et al. [34] as ambient temperature minus leaf temperature. CTD was measured from five leaves in each replicate.

\subsubsection{Leaf Relative Water Content}

Leaf relative water content (LRWC) was estimated following the procedure of Meher et al. [35]. Briefly, $0.5 \mathrm{~g}$ leaf sample was immersed in $100 \mathrm{~mL}$ of distilled water for $4 \mathrm{~h}$. The weights of turgid leaf samples were then measured and then oven-dried at $80^{\circ} \mathrm{C}$ for $48 \mathrm{~h}$. The dry weights of the samples were recorded until a constant weight was achieved. The procedure was repeated thrice for each replicate.

LRWC $(\%)=[($ Fresh weight - Dry weight $) /($ Turgid weight - Dry weight $)] \times 100$

\subsubsection{Cell Membrane Stability}

Cell membrane stability (CMS) was determined following the procedure of Sairam et al. [36]. Briefly, in two sets, 30 leaf discs $(0.7 \mathrm{~cm}$ in diameter) were taken from three completely opened third leaves and put in test tubes containing $10 \mathrm{~mL}$ deionized water. One set of 15 leaf discs was incubated at $40{ }^{\circ} \mathrm{C}$ for $30 \mathrm{~min}$ and the second set at $100{ }^{\circ} \mathrm{C}$ in a boiling water bath for $15 \mathrm{~min}$, and then their electrical conductivities, $\mathrm{C}_{1}$ and $\mathrm{C}_{2}$, respectively, were read with a conductivity meter. The process was repeated thrice for each replicate. CMS was calculated following the equation:

$$
\operatorname{CMS}(\%)=\left[1-\left(\mathrm{C}_{1} / \mathrm{C}_{2}\right)\right] \times 100
$$

\subsection{Biochemical Observations}

\subsubsection{Proline Content}

Leaf proline content was measured spectrophotometrically by an acid-ninhydrin method using the procedure outlined by Bates et al. [37]. The proline content was calculated using a standard curve and reported as $\mu \mathrm{mol} \mathrm{g}^{-1}$ fresh weight.

\subsubsection{Oxidative Stress Indicators}

Generation of superoxide radicals $\left(\mathrm{O}_{2}{ }^{-}\right)$were measured following the method of Elstner and Heupel [38] with some modifications. Briefly, $0.3 \mathrm{~g}$ fresh leaf tissue was homogenized in $3 \mathrm{~mL}$ of $65 \mathrm{mM} \mathrm{K}-\mathrm{P}$ buffer ( $\mathrm{pH}$ 7.8) and centrifuged at $5000 \times \mathrm{g}$ for $10 \mathrm{~min}$. With $750 \mu \mathrm{L}$ supernatant, $675 \mu \mathrm{L} \mathrm{K}-\mathrm{P}$ buffer and $70 \mu \mathrm{L}$ of $10 \mathrm{mM}$ hydroxylamine hydrochloride were added, vortexed, and incubated at $25^{\circ} \mathrm{C}$ for $20 \mathrm{~min}$. To the mixture, $375 \mu \mathrm{L}$ of $17 \mathrm{mM}$ sulfanilamide, $37.5 \mu \mathrm{L} \alpha$-naphthylamine, and $337.5 \mu \mathrm{L} \mathrm{K}-\mathrm{P}$ buffer were added and vortexed. Then, $2.25 \mathrm{~mL}$ diethyl ether was added to the mixture, vortexed again, and incubated for $10 \mathrm{~min}$. The absorbance of the upper clear fraction was recorded at $530 \mathrm{~nm}$. The $\mathrm{O}_{2}{ }^{\bullet-}$ generation was calculated by comparing a standard curve of $\mathrm{NaNO}_{2}{ }^{-}$.

Fresh leaf tissues $(0.5 \mathrm{~g})$ were homogenized in $3 \mathrm{~mL}$ of $5 \%(w / v)$ trichloroacetic acid (TCA). After centrifugation at $11,500 \times g$ for $10 \mathrm{~min}$, the supernatant was used to determine $\mathrm{H}_{2} \mathrm{O}_{2}$ and malondialdehyde (MDA). The $\mathrm{H}_{2} \mathrm{O}_{2}$ content was determined spectrophotometrically according to the procedure of Yang et al. [39] with some modifications. Briefly, $400 \mu \mathrm{L}$ supernatant was added to $400 \mathrm{~mL}$ of $10 \mathrm{mM}$ potassium phosphate buffer (pH 7.0) and $800 \mathrm{~mL}$ of $1 \mathrm{M}$ potassium iodide (KI). The reaction was allowed to proceed in the dark for $1 \mathrm{~h}$ before measuring the absorbance at $390 \mathrm{~nm}$. The $\mathrm{H}_{2} \mathrm{O}_{2}$ concentration was calculated using the extinction coefficient of $0.28 \mu \mathrm{M}^{-1} \mathrm{~cm}^{-1}$. The methods of Heath and Packer [40] and Mohi-Ud-Din et al. [41] 
were followed for MDA determination. The MDA content was calculated using an extinction coefficient of $155 \mathrm{mM}^{-1} \mathrm{~cm}^{-1}$ and represented as nmol g-1 $\mathrm{FW}$ ).

\subsubsection{Extraction and Quantitation of Soluble Protein}

Fresh leaf tissue (1:2) $(w / v)$ was extracted in $0.5 \mathrm{M}$ potassium-phosphate (K-P) buffer $(\mathrm{pH}$ 7.0) in ice-cold mortar. The extraction buffer included $1 \mathrm{mM}$ ascorbic acid, $1 \mathrm{M}$ $\mathrm{KCl}, \beta$-mercaptoethanol, and glycerol. The homogenate was centrifuged at $11,500 \times g$ for $15 \mathrm{~min}$, and the supernatant was used for enzymatic activities assays. Bradford's [42] rapid quantification method was used to determine the protein content of each enzyme solution.

\subsubsection{Assays of Enzymatic Activities}

The lipoxygenase (LOX, EC: 1.13.11.12) activity was assayed spectrophotometrically at $234 \mathrm{~nm}$ as per Doderer et al. [43] using linoleic acid as a substrate. The activity was calculated using an extinction coefficient of $25,000 \mathrm{M}^{-1} \mathrm{~cm}^{-1}$. The superoxide dismutase (SOD, EC: 1.15.1.1) activity was assayed based on the inhibition method of Spitz and Oberley [44]. The catalase (CAT, EC: 1.11.1.6) activity was measured at $240 \mathrm{~nm}$ according to the method of Noctor et al. [45] and calculated using an extinction coefficient of $39.4 \mathrm{M}^{-1} \mathrm{~cm}^{-1}$.

The guaiacol peroxidase (POD, EC: 1.11.1.7) activity was quantified as per the description of Castillo et al. [46] at $470 \mathrm{~nm}$ after $1 \mathrm{~min}$ and calculated considering an extinction coefficient of $26.6 \mathrm{mM}^{-1} \mathrm{~cm}^{-1}$. The activity of glutathione peroxidase (GPX, EC: 1.11.1.9) was measured following Elia et al. [47] at $340 \mathrm{~nm}$ for $1 \mathrm{~min}$. An extinction coefficient of $6.62 \mathrm{mM}^{-1} \mathrm{~cm}^{-1}$ was used to compute the activity. The glutathione $S$-transferase (GST, EC: 2.5.1.18) activity was measured spectrophotometrically by following the method of Hossain et al. [48] with model substrate 1-chloro-2,4-dinitrobenzene (CDNB) at $340 \mathrm{~nm}$. The activity was calculated using an extinction coefficient of $9.6 \mathrm{mM}^{-1} \mathrm{~cm}^{-1}$.

The activities of glutathione reductase (GR, EC: 1.6.4.2), ascorbate peroxidase (APX, EC: 1.11.1.11), monodehydroascorbate reductase (MDHAR, EC: 1.6.5.4), and dehydroascorbate reductase (DHAR, EC: 1.8.5.1) were measured according to Noctor et al. [45] at 340, 290, 340, and $265 \mathrm{~nm}$, respectively. For all enzymes, absorbance changes were observed for $1 \mathrm{~min}$, and extinction coefficients of $6.2 \mathrm{mM}^{-1} \mathrm{~cm}^{-1}, 2.8 \mathrm{mM}^{-1} \mathrm{~cm}^{-1}, 6.2 \mathrm{mM}^{-1} \mathrm{~cm}^{-1}$, and $14 \mathrm{mM}^{-1} \mathrm{~cm}^{-1}$ were used for the quantification of GR, APX, MDHAR, and DHAR, respectively.

\subsection{Statistical Analysis}

The data were analyzed using Statistix 10 (https://www.statistix.com/) (accessed on 26 May 2021). The least significant difference (LSD) test was used to compare the means at the $p \leq 0.05$ significance level. R v.4.1.0 for Windows was used to create a heatmap and to perform principal component analysis (PCA) (http:/ /CRAN.R-project. $\mathrm{org} /$ ) (accessed on 26 May 2021). Trait mean values were normalized and the library pheatmap was adapted to generate heatmap and hierarchical clusters (distance $=$ Euclidean and method = ward.D2) [49]. PCA was performed with the packages ggplot2, factoextra, and FactoMineR [50,51].

\section{Results}

\subsection{Soil Water Content}

By the 25th day of treatment, visible effects, including reduced plant height and appearance, increased droopiness, chlorosis, and wilting of leaves, were observed in the French bean plants. Plants were harvested on that day to record observations and conduct chemical analyses (Figure 1). The silt loam used in this study gave a pot capacity of $30.6 \%$ volumetric soil water content, determined gravimetrically prior to the start of the experiment (Figure 2). The soil water content was considerably lower for the droughtstressed pots than in the control throughout the experiment (Figure 2). At plant harvest, the soil water contents recorded from the control, drought (D), D + MeJA, D + SA, and $\mathrm{D}+\mathrm{MeJA}+\mathrm{SA}$ treatments were equivalent to $59 \%, 24 \%, 26 \%, 25 \%$, and $25 \%$ of pot capacity, 
respectively (Figure 2), confirming that the symptoms observed in the drought-stressed French bean plants were indicative of water deficit.

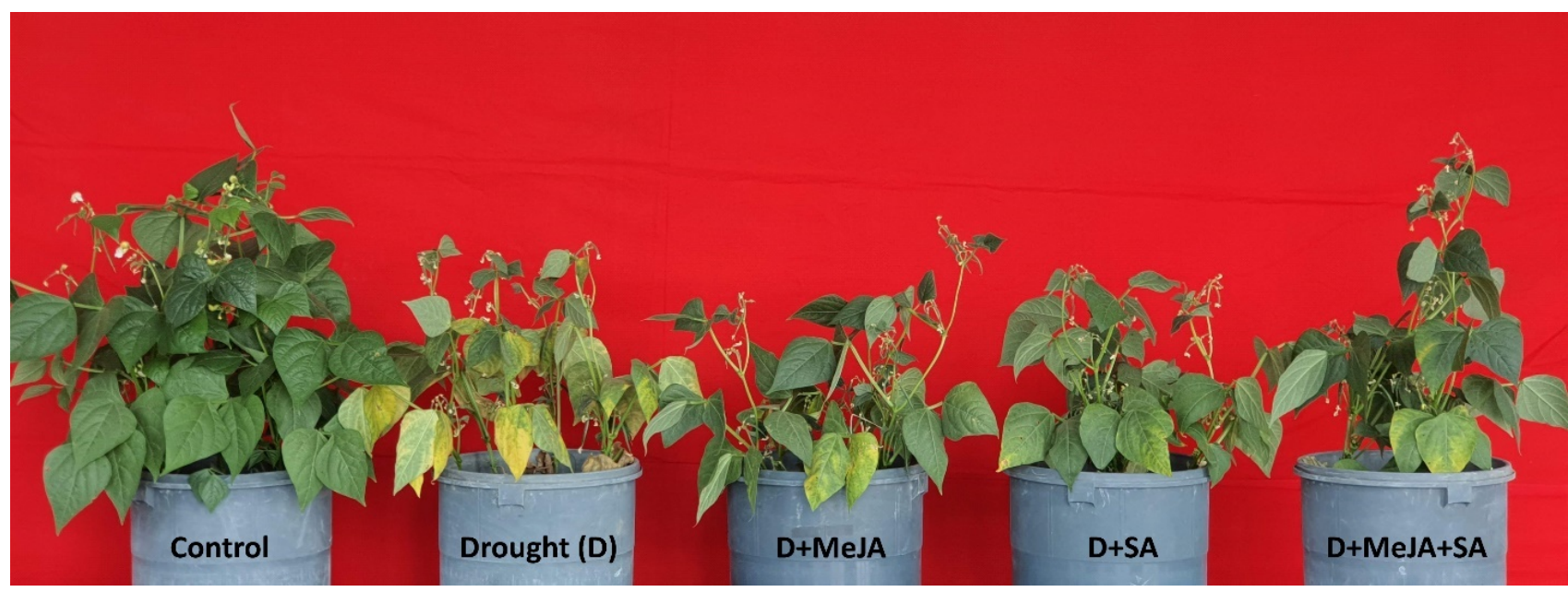

Figure 1. Phenotypic appearance of French bean plants: control, drought (D), and drought-stressed plants treated with methyl jasmonate (D + MeJA), salicylic acid (D + SA), and their combination (D + MeJA + SA) at the time of harvest. Control—plants grown under non-stress, well-irrigated conditions; drought—plants grown with a steady decline in moisture availability; D + MeJA—drought-stressed plants pre-treated (seed and foliar) with $20 \mu \mathrm{M}$ methyl jasmonate; D + SAdrought-stressed plants pre-treated (seed and foliar) with $2 \mathrm{mM}$ salicylic acid; D + MeJA + SA-drought-stressed plants pre-treated (seed and foliar) with a combination of $10 \mu \mathrm{M}$ methyl jasmonate and $1 \mathrm{mM}$ salicylic acid.

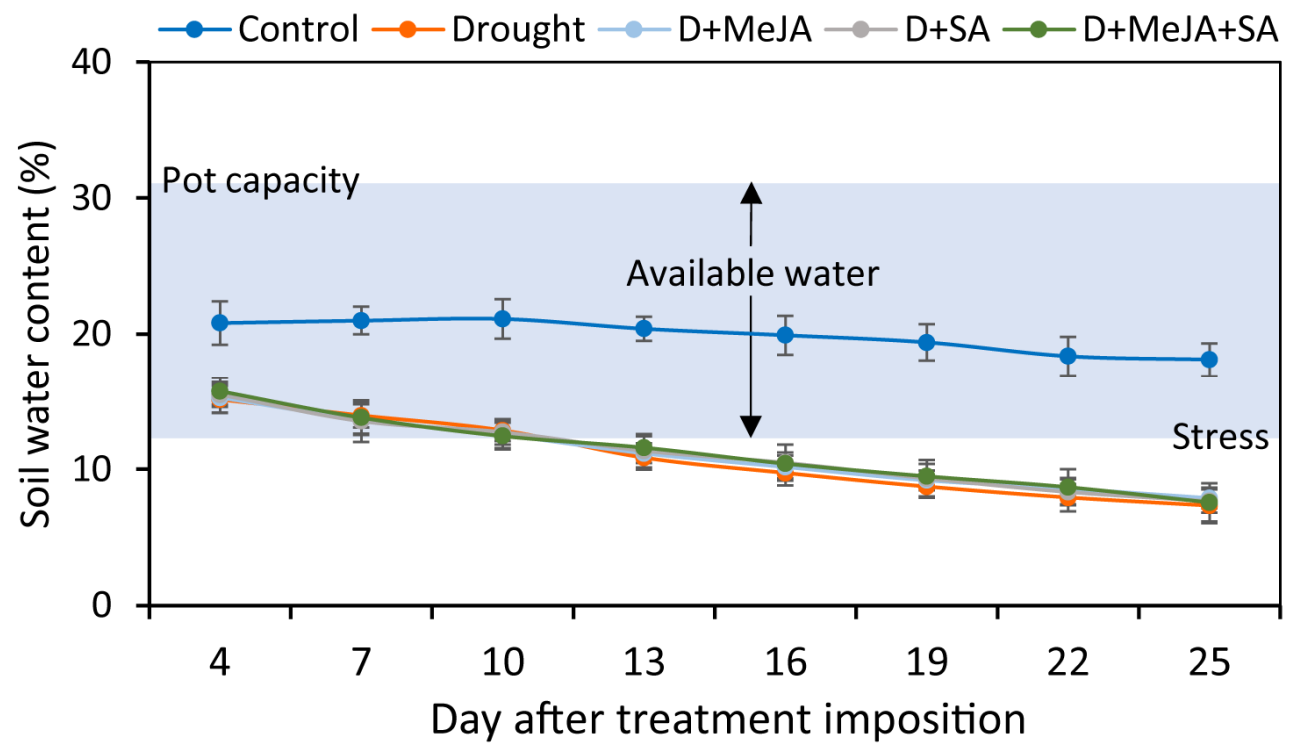

Figure 2. Soil water status of the control, drought (D), and drought-stressed plants treated with methyl jasmonate (D + MeJA), salicylic acid (D + SA), and their combination (D + MeJA + SA) throughout the experimental period. Soil water content was recorded daily for every pot. Each data point indicates the 3-day running average values across four replicates. Vertical bars represent $+/-$ values of the mean. The experimental soil was silt loam (clay:silt:sand $=24: 50: 26)$ with a full pot water capacity of $30.6 \%$ volumetric soil water content. (Adapted from Pardossi et al. [52]; Weng and Luo [53]).

\subsection{MeJA and SA Enhanced Plant Growth}

Drought stress decreased the root and shoot lengths of the French bean plants by $5 \%$ and $42 \%$, respectively, and the decrease in shoot length was statistically significant (Table 1, Figure S1A). The shoot and root lengths were longer in the drought-stressed plants given hormone treatments than in the drought-stressed plants without hormone 
treatments (Table 1). Pretreatment of drought-stressed plants with MeJA or SA alone did not result in statistically significant increases in shoot length compared to drought, but the combined (MeJA + SA) application significantly increased the shoot lengths by $20 \%$ (Figure S1B). Application of MeJA and SA also improved the plant phenotypic appearance under drought conditions (Figure 2).

Table 1. Effect of methyl jasmonate (MeJA), salicylic acid (SA), and their combined application on the growth parameters of French beans under drought stress.

\begin{tabular}{ccccccc}
\hline Treatment & $\begin{array}{c}\text { Root Length } \\
(\mathbf{c m})\end{array}$ & $\begin{array}{c}\text { Shoot Length } \\
\mathbf{( c m )}\end{array}$ & $\begin{array}{c}\text { Root Dry } \\
\text { Weight } \mathbf{( g )}\end{array}$ & $\begin{array}{c}\text { Shoot Dry } \\
\text { Weight } \mathbf{( g )}\end{array}$ & $\begin{array}{c}\text { Leaf Dry } \\
\text { Weight (g) }\end{array}$ & $\begin{array}{c}\text { Total Dry } \\
\text { Weight }(\mathbf{g})\end{array}$ \\
\hline Control & $58.63 \pm 3.45^{\mathrm{a}}$ & $36.49 \pm 0.87^{\mathrm{a}}$ & $2.88 \pm 0.26^{\mathrm{a}}$ & $9.04 \pm 0.74^{\mathrm{a}}$ & $9.93 \pm 0.77^{\mathrm{a}}$ & $21.86 \pm 1.62^{\mathrm{a}}$ \\
Drought (D) & $55.69 \pm 1.23^{\mathrm{a}}$ & $21.27 \pm 0.65^{\mathrm{c}}$ & $1.38 \pm 0.12^{\mathrm{b}}$ & $2.77 \pm 0.21^{\mathrm{c}}$ & $2.61 \pm 0.28^{\mathrm{d}}$ & $6.76 \pm 0.35^{\mathrm{c}}$ \\
D + MeJA & $57.59 \pm 2.13^{\mathrm{a}}$ & $22.10 \pm 0.49^{\mathrm{c}}$ & $1.53 \pm 0.17^{\mathrm{b}}$ & $3.55 \pm 0.19^{\mathrm{c}}$ & $3.91 \pm 0.37^{\mathrm{bc}}$ & $8.99 \pm 0.64^{\mathrm{c}}$ \\
D + SA & $58.91 \pm 2.55^{\mathrm{a}}$ & $22.46 \pm 0.63^{\mathrm{c}}$ & $1.54 \pm 0.18^{\mathrm{b}}$ & $3.69 \pm 0.49^{\mathrm{c}}$ & $3.62^{\mathrm{c}} \pm 0.13^{\mathrm{cd}}$ & $8.85^{\mathrm{d}} \pm 0.65^{\mathrm{c}}$ \\
D + MeJA + SA & $59.81 \pm 1.07^{\mathrm{a}}$ & $25.63 \pm 0.55^{\mathrm{b}}$ & $1.86 \pm 0.19^{\mathrm{b}}$ & $5.09 \pm 0.28^{\mathrm{b}}$ & $4.89 \pm 0.12^{\mathrm{b}}$ & $11.84 \pm 0.23^{\mathrm{b}}$ \\
\hline
\end{tabular}

Values represent the mean \pm SE. Values in a column with distinct letter(s) were significantly different at $p \leq 0.05$. Control—plants grown under non-stress, well-irrigated conditions; drought—plants grown with a steady decline in moisture availability; D + MeJA—droughtstressed plants pre-treated (seed and foliar) with $20 \mu \mathrm{M}$ methyl jasmonate; D + SA—drought-stressed plants pre-treated (seed and foliar) with $2 \mathrm{mM}$ salicylic acid; D + MeJA + SA-drought-stressed plants pre-treated (seed and foliar) with a combination of $10 \mu \mathrm{M}$ methyl jasmonate and $1 \mathrm{mM}$ salicylic acid.

Drought stress resulted in a substantial decrease in dry weights. Compared to the unstressed control plants, the root, shoot, leaf, and total dry weights decreased by 52\%, 69\%, $74 \%$, and 69\%, respectively, due to the drought stress (Table 1 and Figure S1A). Exogenous use of MeJA and SA, both alone and in combination, increased the dry weights under the drought-stressed condition, but the increases induced by the combined treatment, except for the root dry weight, were statistically significant. Increases of approximately 35\%, 84\%, $87 \%$, and $75 \%$ in root, shoot, leaf, and total dry weight, respectively, were recorded in the combined treatment compared to drought stress alone (Figure S1B).

\subsection{Impact of MeJA and SA on Photosynthetic Pigments}

The non-destructive chlorophyll index (SPAD) value significantly decreased (20\%) under drought stress compared to unstressed control plants (Table 2, Figure S1A). Single and combined applications of MeJA and SA increased the SPAD value of drought-stressed plants compared to untreated drought-stressed plants, but the increase due to the combined treatment (22\%) was highly statistically significant (Figure S1B).

Table 2. Effect of methyl jasmonate (MeJA), salicylic acid (SA), and their combination on SPAD value and leaf pigment contents of French bean plants under drought stress.

\begin{tabular}{|c|c|c|c|c|c|}
\hline \multirow{2}{*}{ Treatments } & \multirow{2}{*}{ SPAD } & \multicolumn{4}{|c|}{ Leaf Pigments (mg g ${ }^{-1}$ Fresh Weight) } \\
\hline & & Chl a & Chl b & Total Chl & Carotenoids \\
\hline Control & $49.85 \pm 0.49^{a}$ & $1.39 \pm 0.03^{\mathrm{a}}$ & $0.49 \pm 0.02^{\mathrm{a}}$ & $1.97 \pm 0.06^{\mathrm{a}}$ & $0.50 \pm 0.03^{a}$ \\
\hline Drought (D) & $39.65 \pm 1.18^{c}$ & $0.65 \pm 0.10^{c}$ & $0.24 \pm 0.05^{\mathrm{c}}$ & $0.98 \pm 0.07^{c}$ & $0.26 \pm 0.01^{\mathrm{c}}$ \\
\hline $\mathrm{D}+\mathrm{MeJA}$ & $43.65 \pm 0.93^{b}$ & $0.87 \pm 0.11 \mathrm{bc}$ & $0.29 \pm 0.04^{b c}$ & $1.25 \pm 0.17^{b c}$ & $0.34 \pm 0.05 b c$ \\
\hline $\mathrm{D}+\mathrm{SA}$ & $44.35 \pm 1.52^{b}$ & $0.91 \pm 0.16^{b c}$ & $0.30 \pm 0.07 \mathrm{bc}$ & $1.30 \pm 0.25 \mathrm{bc}$ & $0.33 \pm 0.06^{b c}$ \\
\hline $\mathrm{D}+\mathrm{MeJA}+\mathrm{SA}$ & $48.18 \pm 0.94^{\mathrm{a}}$ & $1.12 \pm 0.06^{\mathrm{b}}$ & $0.39 \pm 0.02^{a b}$ & $1.61 \pm 0.08^{a b}$ & $0.42 \pm 0.03^{\mathrm{ab}}$ \\
\hline
\end{tabular}

Values represent the mean \pm SE. Values in a column with distinct letter(s) were significantly different at $p \leq 0.05$. Additional details are listed in Table 1.

Drought stress significantly decreased the leaf levels of chlorophyll a, chlorophyll $b$, total chlorophyll, and carotenoids by $53 \%, 51 \%, 50 \%$, and $48 \%$, respectively, compared to the control (Table 2 and Figure S1A). The exogenous applications of MeJA and SA, separately or in combination, lessened the negative effects of drought stress. However, the increases in pigment levels following application of MeJA or SA alone were not statistically significant. On the contrary, the combined application of MeJA and SA significantly increased 
chlorophyll a, chlorophyll b, total chlorophyll, and carotenoid contents by $72 \%, 63 \%, 64 \%$, and $62 \%$, respectively, compared to the untreated drought-stressed plants (Figure S1B).

\subsection{MeJA and SA Improved Physiological Traits}

A profound and significant decrease in the mean canopy temperature depression (CTD) was recorded due to the drought stress. The mean CTD decreased by $67 \%$ in the drought-stressed plants compared to the control (Figures 3B and S1A), whereas the droughtstressed plants treated with MeJA, SA, or MeJA + SA showed significant increases in mean CTD $(73 \%, 83 \%$, and $127 \%$, respectively) compared to the untreated drought-stressed plants (Figure S1B). Plants treated with the combination of MeJA and SA maintained a greater CTD throughout the course of the experiment compared to plants treated with either MeJA or SA alone (Figure $3 \mathrm{~A}, \mathrm{~B})$.
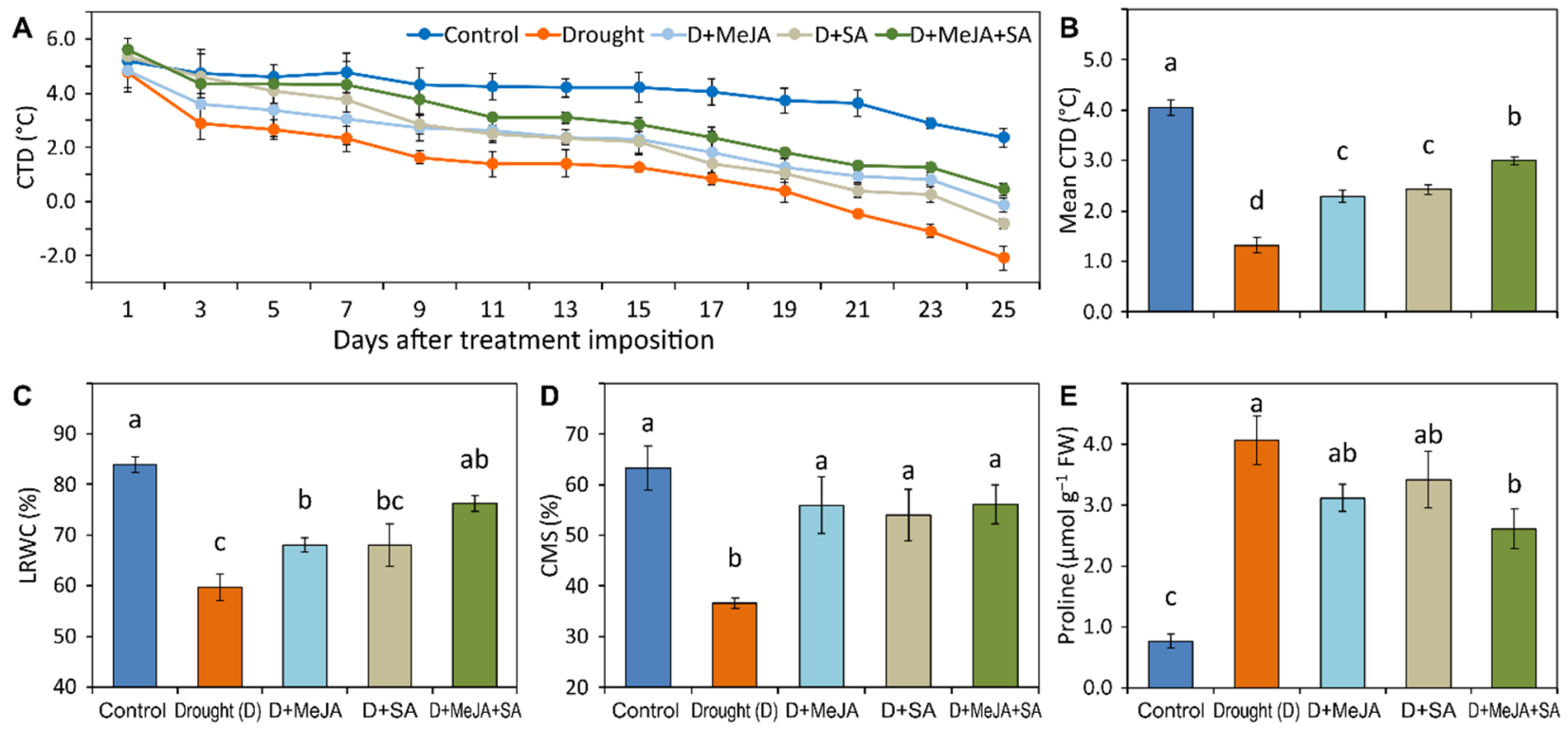

Figure 3. (A) Canopy temperature depression (CTD) throughout the experimental period; (B) mean CTD; (C) leaf relative water content (LRWC); (D) cell membrane stability; (E) proline content of French bean plants grown under control, drought (D), and drought-stressed plants treated with methyl jasmonate (D + MeJA), salicylic acid (D + SA), and their combination $(\mathrm{D}+\mathrm{MeJA}+\mathrm{SA})$. Vertical bars represent $+/-$ SE values. Different letter(s) denote a significant difference at $p \leq 0.05$. FW-Fresh weight. Additional details are shown in Figure 1.

The leaf relative water content (LRWC) significantly decreased (29\% over the control) by drought stress (Figures $3 \mathrm{C}$ and S1A). The drought-stressed plants treated with MeJA and SA and their combination showed increases of $14 \%, 14 \%$, and $28 \%$, respectively, compared to untreated drought-stressed plants; however, the increase was significant only for the MeJA and the combined hormone treatments (Figure S1B). The cell membrane stability (CMS) of leaves decreased by $42 \%$ under drought stress compared to control plants (Figures 3D and S1A). Exogenously applied MeJA and SA mitigated this effect by increasing the CMS by $52 \%$ and $47 \%$, respectively, compared to drought-stressed plants (Figure S1B). The protective effect of MeJA + SA was similar to that observed with application of either hormone alone.

Drought stress triggered a profound increase of $436 \%$ in the proline content in French bean leaves (Figures 3E and S1A). Application of MeJA, SA, and MeJA + SA to droughtstressed plants lowered the proline content by $23 \%, 16 \%$, and $36 \%$, respectively, compared to the drought-stressed plants (Figure S1B).

\subsection{MeJA and SA Suppressed the Generation of Oxidative Stress Indicators}

Oxidative stress due to the drought stress in French bean plants was determined by measurements of the $\mathrm{O}_{2}{ }^{\bullet-}$ generation rate, the $\mathrm{H}_{2} \mathrm{O}_{2}$ and MDA levels, and the LOX 
activity. A sharp increase in $\mathrm{O}_{2}{ }^{\bullet-}$ generation (270\%) was observed in drought-stressed plants compared to unstressed controls (Figures 4A and S2A). Application of MeJA, SA, and MeJA + SA significantly lowered $\left(31 \%, 36 \%\right.$, and $51 \%$, respectively) $\mathrm{O}_{2}{ }^{\bullet-}$ generation (Figures $4 \mathrm{~A}$ and S2B). The $\mathrm{H}_{2} \mathrm{O}_{2}$ levels also significantly increased by $55 \%$ in droughtstressed plants compared to the unstressed controls (Figures $4 \mathrm{~B}$ and S2A). Treatment with MeJA, SA, and MeJA + SA lowered the $\mathrm{H}_{2} \mathrm{O}_{2}$ levels by $14 \%, 13 \%$, and $19 \%$, respectively, compared to untreated drought-stressed plants (Figure S2B).
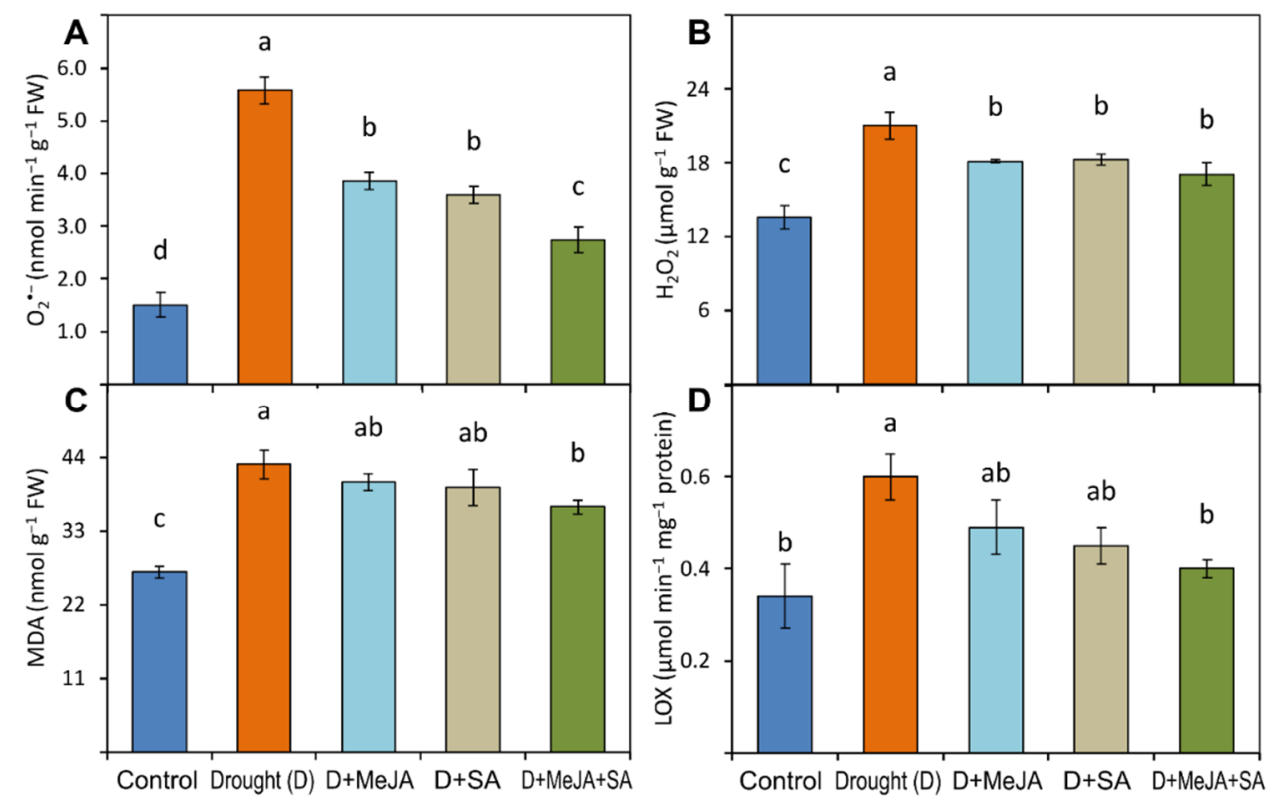

Figure 4. (A) superoxide $\left(\mathrm{O}_{2}{ }^{\bullet-}\right)$ generation rate; (B) hydrogen peroxide content $\left(\mathrm{H}_{2} \mathrm{O}_{2}\right) ;(\mathbf{C})$ malondialdehyde content (MDA); (D) lipoxygenase (LOX) activity of French bean plants grown under control, drought (D), and drought-stressed plants treated with methyl jasmonate (D + MeJA), salicylic acid $(\mathrm{D}+\mathrm{SA})$, and their combination (D + MeJA + SA). Vertical bars represent + / - SE values. Different letter(s) denote a significant difference at $p \leq 0.05$. FW—Fresh weight. Additional details are shown in Figure 1.

Compared to unstressed controls, the levels of MDA and the LOX activity increased by $60 \%$ and $76 \%$, respectively, due to the drought stress (Figures $4 \mathrm{C}$,D and S2A). However, MeJA, SA, and MeJA + SA treatments restrained the production of MDA and the LOX activity in drought-stressed plants. Combined MeJA + SA reduced MDA content and LOX activity by $15 \%$ and $33 \%$, respectively.

\subsection{Antioxidant Enzyme Activities and MeJA and SA Pre-Treatment}

Drought stress promoted a substantial increase in SOD activity by $54 \%$ compared to the unstressed control (Figures 5A and S2A). Exogenous application of MeJA or SA further enhanced SOD activity compared to untreated drought-stressed plants, while the combined MeJA + SA treatment caused a statistically significant $83 \%$ rise in SOD activity compared to the untreated drought-stressed plants (Figure S2B). Unlike SOD, the activities of CAT and POD substantially decreased ( $42 \%$ and $54 \%$, respectively) in the drought-stressed plants compared to the controls (Figures 5B,C and S2A). Application of MeJA or SA alone to drought-stressed plants did not show any remarkable effect on these enzyme activities compared to the activities in the untreated drought-stressed plants; however, the combined MeJA + SA treatment significantly increased the activities of CAT and POD (79\% and 144\%, respectively) compared to activities in the untreated drought-stressed plants (Figure S2B). 

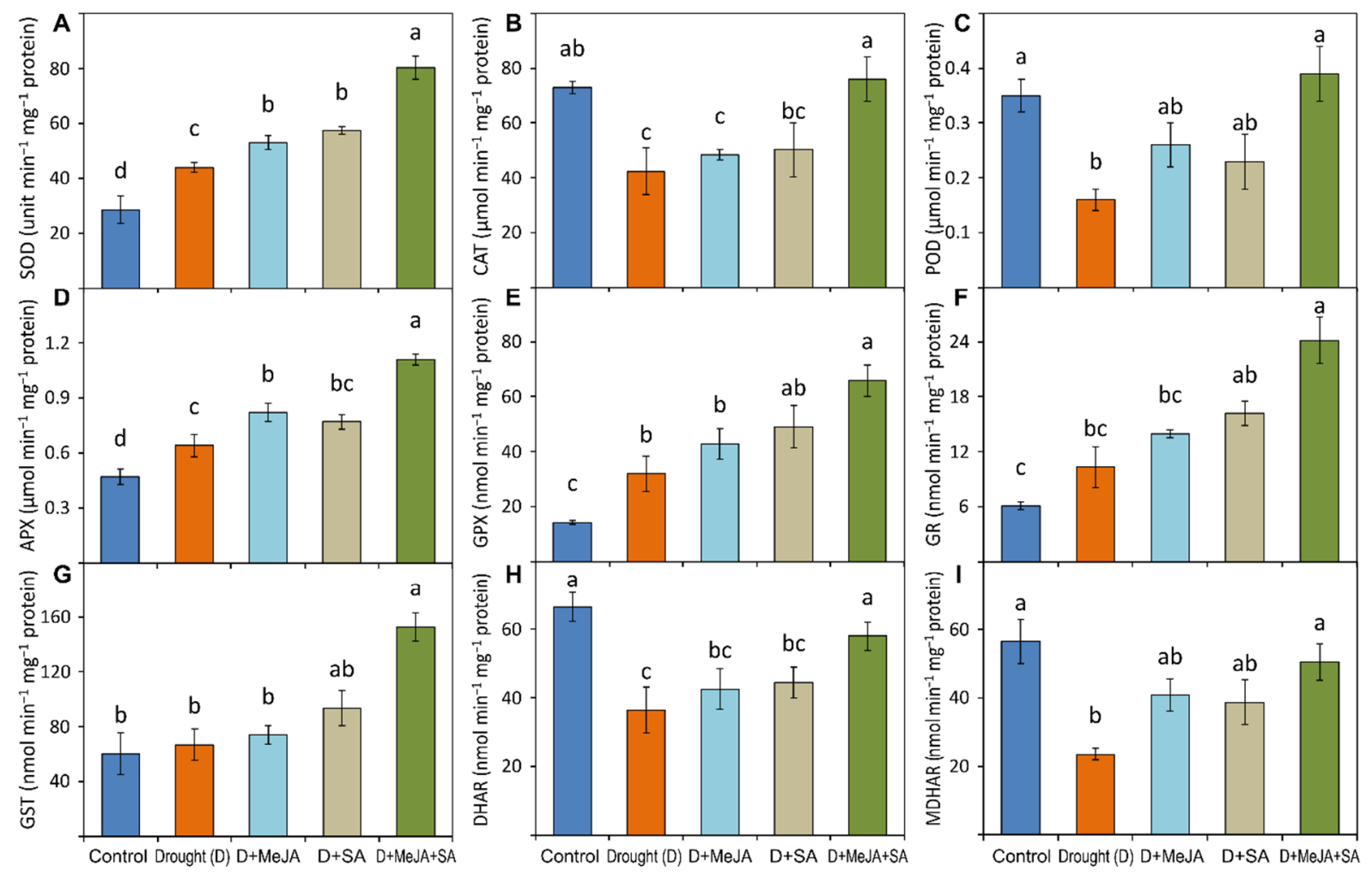

Figure 5. Specific activity of (A) superoxide dismutase (SOD); (B) catalase (CAT); (C) peroxidase (POD); (D) ascorbate peroxidase (APX); (E) glutathione peroxidase (GPX); (F) glutathione reductase (GR); (G) glutathione-S-transferase (GST); (H) dehydroascorbate reductase (DHAR); (I) monodehydroascorbate reductase (MDHAR) of French bean plants grown under control, drought (D), and drought-stressed plants treated with methyl jasmonate (D + MeJA), salicylic acid (D + SA), and their combination (D + MeJA + SA). Vertical bars represent +/ - SE values. Different letter(s) denote a significant difference at $p \leq 0.05$. Additional details are shown in Figure 1 .

A slight increase was noted in APX and GST activities in the drought-stressed plants ( $36 \%$ and $11 \%$, respectively) compared to the unstressed control (Figures 5D,G and S2A). Application of SA alone to drought-stressed plants did not change the APX and GST activities substantially, while MeJA significantly increased the activity of APX only (Figure 5D,G). However, the combined application of MeJA + SA significantly increased the APX and GST activities (73\% and 128\%) compared to untreated drought-stressed plants (Figures 5D,G and S2B). A marked increase in GPX activity (126\%) was recorded in the drought-stressed plants compared to the unstressed controls, but no significant increases were noted for GR activity (Figures 5E,F and S2A). Treatment with MeJA or SA alone did not cause any marked increases, whereas the combined MeJA + SA treatment significantly increased both GPX and GR activities (105\% and 134\%, respectively) compared to the untreated drought-stressed plants (Figure S2B).

Compared to the unstressed controls, the activities of DHAR and MDHAR decreased ( $45 \%$ and 58\%, respectively) in the drought-stressed plants (Figures 5H,I and S2A). Treatment of drought-stressed plants with MeJA or SA alone did not significantly increase these enzyme activities, whereas the combined MeJA + SA treatment resulted in a statistically significant increase in the activities of both DHAR and MDHAR by $59 \%$ and $115 \%$, respectively, compared to the untreated drought-stressed plants (Figures 5H,I and S2B).

\subsection{Comparative Assessment of Responses across Treatments}

A comparative heatmap analysis revealed three distinct groups among the parameters measured in this study (Figure 6). Group 1 consisted of most of the antioxidant enzymes (SOD, APX, GPX, GR, and GST), root length, and CMS. Oxidative stress indicators and proline content were placed in group 3, and the rest of the parameters, including CAT, POD, DHAR, and MDHAR, were in group 2. A distinct categorization of the growth, 
physiological processes, and antioxidant scavenging machinery was observed, as droughtstressed plants without pre-treatment and with pre-treatment with either MeJA or SA alone were grouped in a cluster (Figure 6). However, the plants given the combined MeJA + SA treatment showed significantly higher amelioration of drought stress-induced damage and were grouped in the same cluster as the unstressed control plants (Figure 6). A contrasting response between the unstressed controls and the plants receiving the combined MeJA + SA treatment was observed for the ROS scavenging machinery, whereas the ROS levels and other growth and physiological responses were aligned in the same direction in both plant groups (Figure 6).

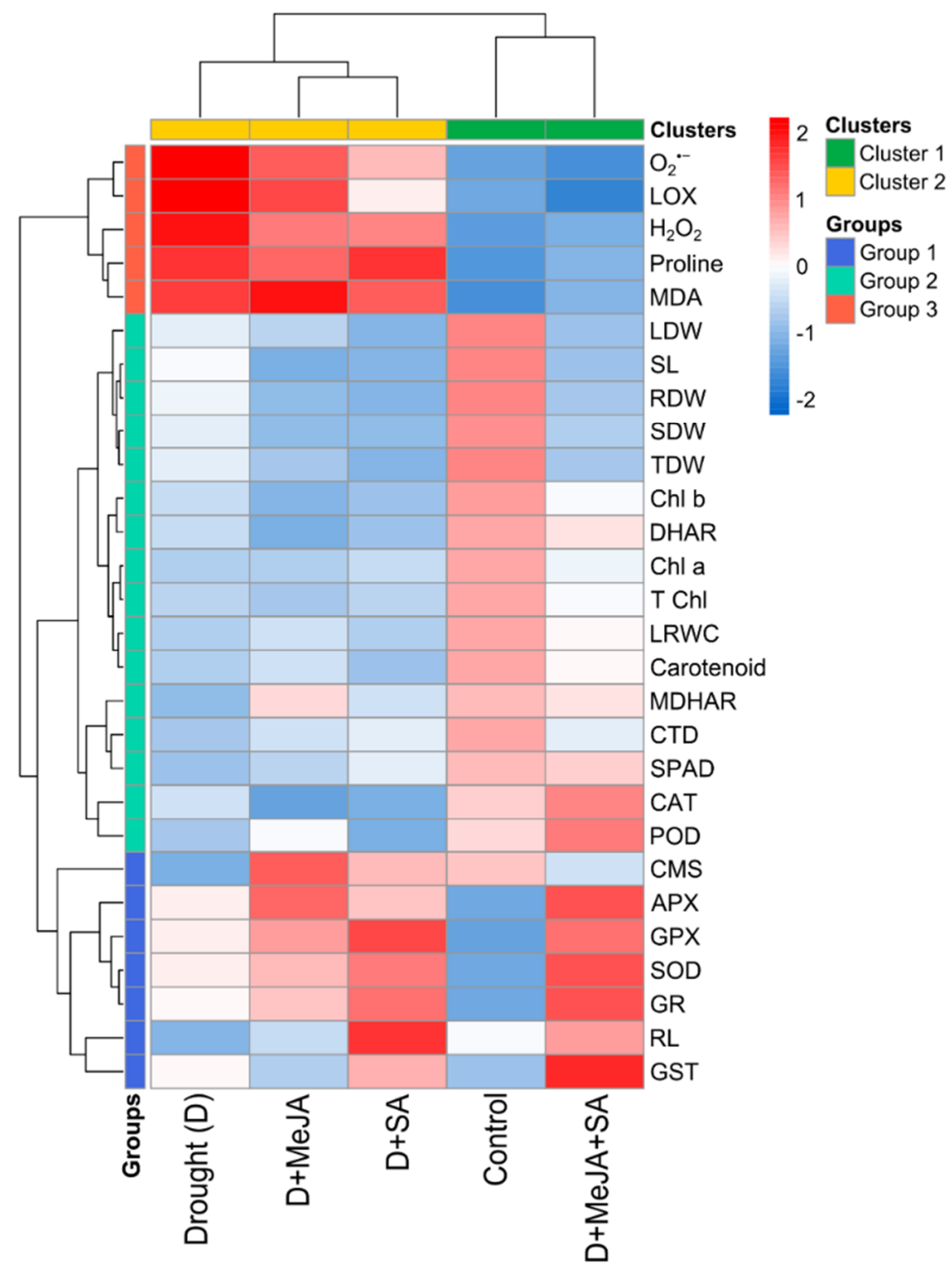

Figure 6. Heatmap and cluster analysis of the growth and physiological attributes, oxidative stress indicators, and antioxidant enzymes in French bean plants grown under control, drought (D), and drought-stressed plants treated with methyl jasmonate (D + MeJA), salicylic acid (D + SA), and their combination (D + MeJA + SA). Additional details are shown in Figure 1.

\subsection{Principal Component Analysis (PCA)}

The PCA of the responses of the French bean plants to different treatments depicted a total of four principal components (PCs), but only two PCs exhibited eigenvalues $>1$ and were significant. Both the PCs explained approximately $97 \%$ of the variability in drought response (Figure 7 and Table S2). A PCA biplot showed that PC1 exhibited approximately $75 \%$ of the total variability and contributed positively via morpho-physiological traits, CAT, POD, DHAR, and MDHAR; it contributed negatively via proline, $\mathrm{SOD}, \mathrm{H}_{2} \mathrm{O}_{2}, \mathrm{MDA}$, and 
LOX (Figure 7, Table S2). The second PC accounted for approximately $22 \%$ of the total variation and contributed principally by SOD, APX, GPX, GR, GST, and RL and partly by SPAD, CAT, POD, and MDHAR.

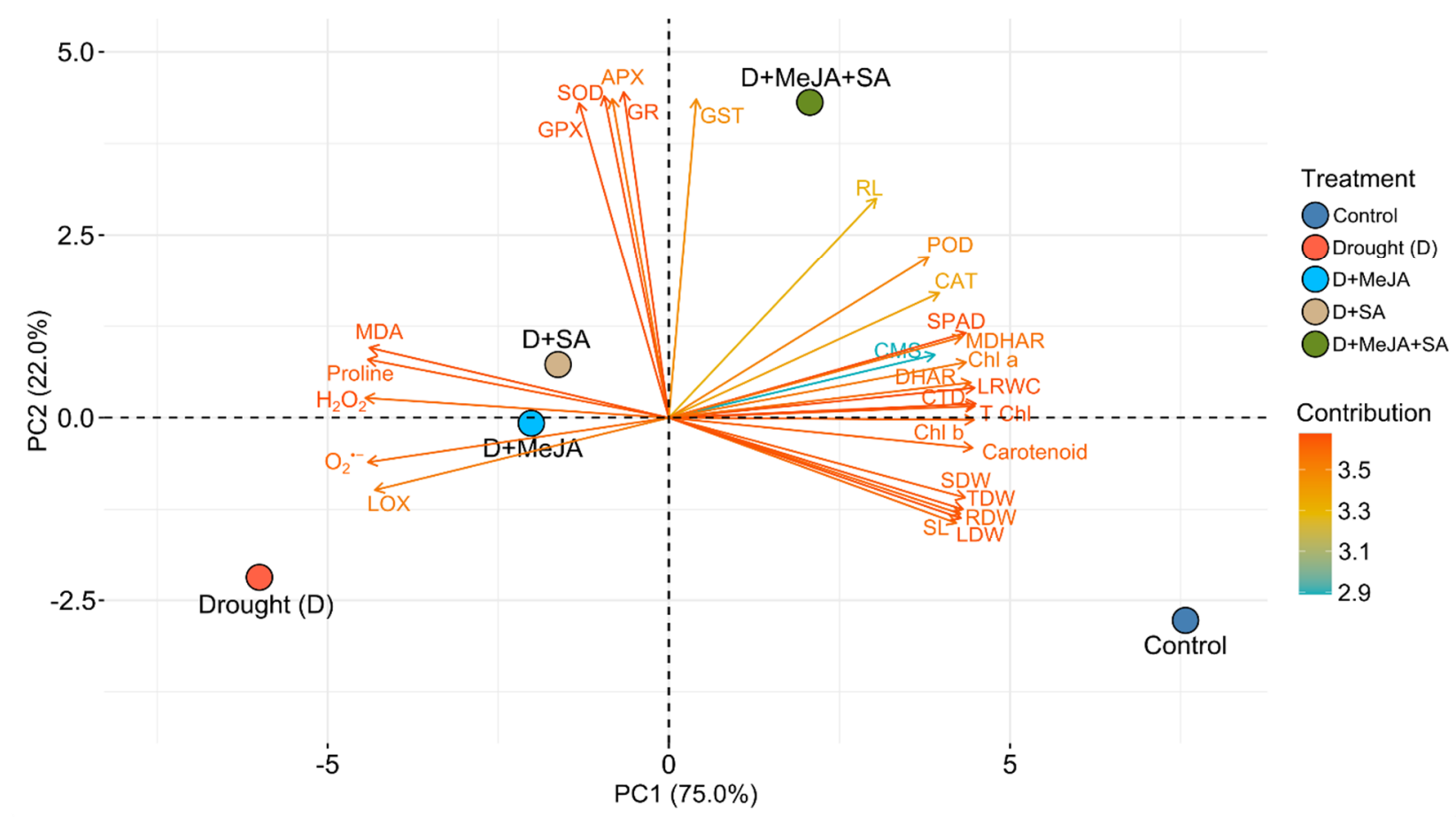

Figure 7. A PCA biplot stipulates the relationship between treatments and observed parameters. Parameters are distributed in different ordinates depending on the divergence among them. In this biplot, the length and color intensity of a vector indicate the quality of representation and the contribution of the traits to the principal components, respectively. The angles between the vectors formed from the middle point of the biplots indicate whether the traits interacted positively or negatively. Additional details are shown in Figure 1.

\section{Discussion}

The findings from this study revealed how exogenous application of MeJA, SA, and their combination can help to reduce the adverse effects of drought in French bean by maintaining cellular water levels, membrane stability, photosynthetic pigment levels, and antioxidant defenses to ultimately improve morpho-physiological growth. The growth parameters of French bean (shoot and root lengths and dry weights) were reduced under drought stress but were less affected following application of MeJA and SA, separately or in combination. An improvement in drought stress tolerance by the combined application of MeJA and SA has recently been demonstrated in maize by Tayyab et al. [27]; however, the present report is the first to demonstrate similar effects in French beans by significant activation of the plant antioxidant defense system. Previous studies have demonstrated an effective minimization of the damaging effects of drought by exogenous application of MeJA or SA alone in mustard [18] and wheat [28] and by the combination of MeJA and SA in maize [27] through enhancement of various biochemical, morphological, and physiological responses [54] including cell elongation, cell expansion, and cell differentiation [55].

The chlorophyll index, including $\mathrm{Chl} \mathrm{a,} \mathrm{b}$, and total $\mathrm{Chl}$, and the carotenoid content measured in the same leaves were reduced by drought stress (Table 2 and Figure S1A). Drought stress is known to lower the levels of photosynthetic pigments, including chlorophylls and carotenoids, in various crop plants due to the oxidation and impaired biosynthesis of the pigments $[56,57]$. The observed decrease in chlorophyll concentration under drought stress could represent a suppression of chlorophyll biosynthesis and/or decreased synthesis and assembly of the PSI and PSII light-harvesting complexes to suppress excess absorption and ROS production [6,58]. The negative impacts on pigments were partly ame- 
liorated in French bean plants treated with MeJA or SA, but the effects were consistently statistically significant for the combined MeJA + SA treatment, and the plant growth and physiology were similar to those of the unstressed control plants (Table 2 and Figure S1B). Increases in leaf chlorophyll and carotenoid contents in drought-stressed plants treated with MeJA, SA, and their combination have been reported previously in soybean [59], soybean [60], and maize [27], respectively.

Canopy temperature depression, LRWC, and CMS are considered effective indicators of drought stress tolerance [6,61-63]. Our findings provide support for earlier results showing that French beans under drought stress have significantly lower CTD, LRWC, and CMS; however, these reductions were suppressed by the application of MeJA or SA and statistically significantly suppressed by the combined MeJA + SA treatment Figures 3 and S1B). CTD is regarded as a reliable indication of plant water status, and a positive CTD means the canopy is cooler than the surrounding air [64].

An improved LRWC was reported in drought-stressed plants following MeJA treatment of soybean [59], SA treatment of soybean [60] and Ctenanthe setosa [65], and a combined MeJA and SA treatment of maize [27]. The enhanced CTD, LRWC, and CMS in the drought-stressed French bean plants treated with MeJA and SA in the present study indicates that these hormones, particularly when supplied in combination, have the potential to reduce the harmful effects of drought by maintaining cellular water status and maintaining a cooler leaf temperature.

Proline has been considered an osmotic stress mediator, stabilizer of macromolecules, compatible solutes to preserve enzymes, and capable of storing carbon and nitrogen for usage during drought and other stresses [66]. Proline accumulation in plants is also a marker of stress induction [67]. Although proline content profoundly increased under drought stress in French beans, the MeJA, SA, and MeJA + SA treatments markedly reduced the proline content in drought-stressed plants (Figures $3 \mathrm{E}$ and S1B). This was due to the reduction in osmotic stress following the application of hormones [18,24,26].

The effect of exogenous MeJA and SA on the drought-induced oxidative stress was investigated by determining $\mathrm{O}_{2}{ }^{\bullet-}$ generation and the $\mathrm{H}_{2} \mathrm{O}_{2}$ and MDA levels as well as the specific activity of LOX. Drought stress significantly increased the levels of $\mathrm{O}_{2}{ }^{\bullet-}, \mathrm{H}_{2} \mathrm{O}_{2}$, and MDA and LOX activity compared to the unstressed control plants, indicating that the plants were under severe oxidative stress (Figures 4 and S2A). The drought-induced increases in oxidative stress indicators in our study were consistent with results from previous studies on soybean [60], mustard [24], and maize [27]. Exogenous application of MeJA or SA suppressed the production of the oxidative stressors, while MeJA + SA showed statistically significant effects in drought-stressed French bean plants Figures 4 and S2B). These findings are in accordance with previous studies showing that combined treatments with MeJA and SA reduced the levels of oxidative stress indicators in maize seedlings under drought [27] and in Eureka lemon under chilling stress [30].

In plant cells, SOD renders key protection against $\mathrm{O}_{2}{ }^{\bullet-}$ by converting it to $\mathrm{H}_{2} \mathrm{O}_{2}$ and, subsequently, neutralizing it to $\mathrm{H}_{2} \mathrm{O}$ by CAT and peroxidases (POD, APX, and GPX) $[15,16,68]$. The plant GSTs are a large and diverse group of enzymes that catalyze the coupling of electrophilic xenobiotic substrates with GSH and are linked with the induction of tolerance to different abiotic stresses [69]. The four enzymes of the ascorbate-glutathione cycle (i.e., APX, MDHAR, DHAR, and GR) played a pivotal role in the systematic detoxification of cellular $\mathrm{H}_{2} \mathrm{O}_{2}$ produced due to the oxidative stress in wheat [41].

In the present study, increased activity of SOD, APX, GPX, GST, and GR and decreased activity of CAT, POD, DHAR, and MDHAR were observed in drought-stressed plants compared with unstressed the control plants (Figure 5), which is in agreement with earlier findings of similar drought-stress effects in rapeseed [70], mustard [18], and mung bean [71]. Exogenous MeJA, SA, and their combination augmented the antioxidant enzyme activities in French beans under drought stress and reduced drought-induced oxidative damage (Figures 5 and S2B). However, MeJA $(20 \mu \mathrm{M})$ and SA $(2 \mathrm{mM})$ applied independently did not consistently improve the antioxidant enzyme system under drought; this may be because of 
a reliance on other stress signals that can activate antioxidant enzymes' activities [55]. MeJA or SA induced an upregulation of the antioxidant enzyme system under drought stress in Ctenanthe setosa [65], Cucumis melo [72], mustard [18,24], jatropha [22], and Verbascum sinuatum [26]. However, a combined MeJA and SA treatment $(10 \mu \mathrm{M}+1 \mathrm{mM})$ was more effective in this upregulation of the antioxidant enzymes (Figures 5 and S2B). These results are in agreement with Tayyab et al. [27], who observed a synergistically positive role of MeJA + SA in increasing antioxidant enzyme activity under drought-induced oxidative stress in maize seedlings. Our results suggest that the signaling routes of MeJA and SA would operate similarly to trigger defensive responses in French bean plants under drought stress. However, investigating additional mechanisms that lead to an increased effectiveness by combined hormone applications on minimizing drought stress is an intriguing area for future research.

Taken together, our results demonstrated that MeJA or SA reduced oxidative stress by upregulating antioxidant enzyme activities, improving the physiological functions of French bean plants under drought stress; however, the alleviation was further boosted by combined hormone application. Heatmap and PCA biplot analyses clearly showed that the combined application of MeJA and SA mitigated drought-induced oxidative stress principally by the upregulation of SOD, APX, GPX, GR, and GST and partly by CAT, POD, and MDHAR activities (Figures 6 and 7). The results presented in this study add new insights into oxidative stress defense mechanisms triggered by MeJA and SA in French bean plants.

\section{Conclusions}

French beans pre-treated with exogenous MeJA and SA showed reductions in drought stress responses including improved photosynthetic performance, membrane stability, water status, leaf temperature control, and antioxidant enzyme activities. Interestingly, the combined application of MeJA $(10 \mu \mathrm{M})$ and SA $(1 \mathrm{mM})$ was more efficacious at alleviating the adverse effects of drought-induced oxidative stress by upregulating antioxidant enzymatic activities. The combined treatment also improved the physiological activities and increased plant biomass compared to drought-stressed plants. Seed and foliar treatment of French bean with a combination of MeJA and SA significantly improved drought stress tolerance by augmenting antioxidant systems. The findings from this study provide the rationale for future research related to the defense signaling pathways employed by French bean plants pre-treated with MeJA and SA to aid in the development of new cultivars with improved adaptation to future drier scenarios.

Supplementary Materials: The following are available online at https://www.mdpi.com/article/ 10.3390/plants10102066/s1, Table S1: Daily weather data at the experimental site during the study period, Table S2: Extracted Eigenvalues and latent vectors of studied traits associated with the first two principal components, Figure S1: Variations in the studied growth and physiological parameters of French bean plants. A. Percent change due to drought over control and B. percent change over drought due to the application of methyl jasmonate (D + MeJA), salicylic acid (D + SA) and their combination (D + MeJA + SA) on drought-stressed plants, and Figure S2: Variations in the oxidative stress indicators and antioxidant enzymes activity of French bean plants. A. Percent change due to drought over control and $\mathrm{B}$. percent change over drought due to the application of methyl jasmonate $(\mathrm{D}+\mathrm{MeJA})$, salicylic acid $(\mathrm{D}+\mathrm{SA})$ and their combination $(\mathrm{D}+\mathrm{MeJA}+\mathrm{SA})$ on drought stressed plants.

Author Contributions: M.M.-U.-D., D.T., J.U.A. and M.R. contributed to the conception of the work, data acquisition, and interpretation of the data; M.M.-U.-D. and D.T. performed the experiments and contributed to the data analysis; M.R. contributed the reagents and materials; M.M.-U.-D. and M.H. contributed to the graphical presentation of the data; M.M.-U.-D., D.T., J.U.A., T.I. and M.H. drafted the manuscript; S.V.K.J., T.I. and M.H. contributed to the critical revision and finalization of the manuscript. All authors have read and agreed to the published version of the manuscript.

Funding: This research was partially funded by the contribution number 21-323-J from the Kansas Agricultural Experiment Station, Kansas State University, Manhattan, KS 66506, USA. 
Institutional Review Board Statement: Not applicable.

Informed Consent Statement: Not applicable.

Data Availability Statement: All relevant data are available in this manuscript.

Acknowledgments: We extend our thanks to the Molecular Breeding Laboratory, Bangladesh Agricultural Research Institute, Gazipur, Bangladesh, for providing lab facilities during the research work.

Conflicts of Interest: The authors declare no conflict of interest.

\section{References}

1. Graham, P.H.; Ranalli, P. Common bean (Phaseolus vulgaris L.). Field Crop. Res. 1997, 53, 131-146. [CrossRef]

2. Rosales-Serna, R.; Kohashi-Shibata, J.; Acosta-Gallegos, J.A.; Trejo-Lopez, C.; Ortizcereceres, J.; Kelly, J. Biomass distribution, maturity acceleration and yield in drought-stressed common bean cultivars. Field Crops Res. 2004, 85, 203-211. [CrossRef]

3. Nazrul, M.I.; Shaheb, M.R. Performance of French bean (Phaseolus vulgaris L.) genotypes in Sylhet region of Bangladesh. Bangladesh Agron. J. 2016, 19, 37-44. [CrossRef]

4. Assefa, T.; Wu, J.; Beebe, S.E.; Rao, I.M.; Marcomin, D.; Claude, R.J. Improving adaptation to drought stress in small red common bean: Phenotypic differences and predicted genotypic effects on grain yield, yield components and harvest index. Euphytica 2015, 203, 477-489. [CrossRef]

5. Jaleel, C.A.; Manivannan, P.; Wahid, A.; Farooq, M.; Somasundaram, R.; Panneerselvam, R. Drought stress in plants: A review on morphological characteristics and pigments composition. Int. J. Agric. Biol. 2009, 11, 100-105.

6. Ghobadi, M.; Taherabadi, S.; Ghobadi, M.-E.; Mohammadi, G.-R. Jalali-Honarmand, S. Antioxidant capacity, photosynthetic characteristics and water relations of sunflower (Helianthus annuus L.) cultivars in response to drought stress. Ind. Crop. Prod. 2013, 50, 29-38. [CrossRef]

7. Lesznyák, M.; Hunyadi-Borbély, É.; Csajbók, J. The role of nutrient-water-supply and the cultivation in the yield of pea (Pisum sativum L.). Cereal Res. Commun. 2008, 36, 1079-1082.

8. Trenberth, K.E.; Dai, A.; Van Der Schrier, G.; Jones, P.D.; Barichivich, J.; Briffa, K.R.; Sheffield, J. Global warming and changes in drought. Nat. Clim. Chang. 2014, 4, 17-22. [CrossRef]

9. Schwalm, C.R.; Anderegg, W.R.L.; Michalak, A.M.; Fisher, J.B.; Biondi, F.; Koch, G.; Litvak, M.; Ogle, K.; Shaw, J.D.; Wolf, A.; et al. Global patterns of drought recovery. Nature 2017, 548, 202-205. [CrossRef]

10. MoEF. Bangladesh Climate Change Strategy and Action Plan 2009; Ministry of Environment and Forests: Dhaka, Bangladesh, 2009.

11. Jain, M.; Kataria, S.; Hirve, M.; Prajapati, R. Water deficit stress effects and responses in maize. In Plant Abiotic Stress Tolerance; Hasanuzzaman, M., Hakeem, K., Nahar, K., Alharby, H., Eds.; Springer: Cham, Switzerland, 2019; pp. 129-151.

12. Gao, M.; Zhou, J.J.; Liu, H.; Zhang, W.; Hu, Y.; Liang, J.; Zhou, J. Foliar spraying with silicon and selenium reduces cadmium uptake and mitigates cadmium toxicity in rice. Sci. Total Environ. 2018, 631-632, 1100-1108. [CrossRef]

13. Singh, M.; Kushwaha, B.K.; Singh, S.; Kumar, V.; Singh, V.P.; Prasad, S.M. Sulphur alters chromium (VI) toxicity in Solanum melongena seedlings: Role of sulphur assimilation and sulphur-containing antioxidants. Plant. Physiol. Biochem. 2017, 112, 183-192. [CrossRef]

14. Fazeli, F.; Ghorbanli, M.; Niknam, V. Effect of drought on biomass, protein content, lipid peroxidation and antioxidant enzymes in two sesame cultivars. Plant. Biol. 2007, 51, 98-103. [CrossRef]

15. Foyer, C.H.; Noctor, G. Ascorbate and glutathione: The heart of the redox hub. Plant. Physiol. 2011, 155, 2-18. [CrossRef]

16. Gill, S.S.; Tuteja, N. Reactive oxygen species and antioxidant machinery in abiotic stress tolerance in crop plants. Plant. Physiol. Biochem. 2010, 48, 909-930. [CrossRef]

17. Noctor, G.; Lelarge-Trouverie, C.; Mhamdi, A. The metabolomics of oxidative stress. Phytochemistry 2014, 112, 33-53. [CrossRef]

18. Alam, M.M.; Hasanuzzaman, M.; Nahar, K.; Fujita, M. Exogenous salicylic acid ameliorates short term drought stress in mustard (Brassica juncea L.) seedlings by up-regulating the antioxidant defense and glyoxalase system. Aust. J. Crop. Sci. 2013, 7, 1053-1063.

19. Hasanuzzaman, M.; Nahar, K.; Bhuiyan, T.F.; Anee, T.I.; Inafuku, M.; Oku, H.; Fujita, M. Salicylic acid: An all-rounder in regulating abiotic stress responses in plants. In Phytohormones-Signaling Mechanisms and Crosstalk in Plant Development and Stress Responses; El-Esawi, M.A., Ed.; IntechOpen: London, UK, 2017; pp. 31-75.

20. Mir, M.A.; John, R.; Alyemeni, M.N.; Alam, P.; Ahmad, P. Jasmonic acid ameliorates alkaline stress by improving growth performance, ascorbate glutathione cycle and glyoxylase system in maize seedlings. Sci. Rep. 2018, 8, 2831. [CrossRef]

21. Lazebnik, J.; Frago, E.; Dicke, M.; van Loon, J.J.A. Phytohormone mediation of interactions between herbivores and plant pathogens. J. Chem. Ecol. 2014, 40, 730-741. [CrossRef]

22. Soares, A.M.S.; Oliveira, J.T.A.; Gondim, D.M.F.; Domingues, D.P.; Machado, O.L.T.; Jacinto, T. Assessment of stress-related enzymes in response to either exogenous salicylic acid or methyl jasmonate in Jatropha curcas L. leaves, an attractive plant to produce biofuel. South. Afr. J. Bot. 2016, 105, 163-168. [CrossRef]

23. Li, L.; Lu, X.; Ma, H.; Lyu, D. Jasmonic acid regulates the ascorbate-glutathione cycle in Malus baccata Borkh roots under low root-zone temperature. Acta Physiol. Plant. 2017, 39, 174. [CrossRef] 
24. Alam, M.M.; Nahar, K.; Hasanuzzaman, M.; Fujita, M. Exogenous jasmonic acid modulates the physiology, antioxidant defense and glyoxalase systems in imparting drought stress tolerance in different Brassica species. Plant. Biotechnol. Rep. 2014, 8, $279-293$. [CrossRef]

25. Shyu, C.; Brutnell, T.P. Growth-defense balance in grass biomass production: The role of jasmonates. J. Exp. Bot. 2015, 66, 4165-4176. [CrossRef]

26. Karamian, R.; Ghasemlou, F.; Amiri, H. Physiological evaluation of drought stress tolerance and recovery in Verbascum sinuatum plants treated with methyl jasmonate, salicylic acid and titanium dioxide nanoparticles. Plant. Biosyst. 2019, 154, $277-287$. [CrossRef]

27. Tayyab, N.; Naz, R.; Yasmin, H.; Nosheen, A.; Keyani, R.; Sajjad, M.; Hassan, M.N.; Roberts, T.H. Combined seed and foliar pre-treatments with exogenous methyl jasmonate and salicylic acid mitigate drought induced stress in maize. PLoS ONE 2020, 15, e0232269. [CrossRef]

28. Anjum, S.A.; Tanveer, M.; Hussain, S.; Tung, S.A.; Samad, R.A.; Wang, L.; Khan, I.; ur Rehman, N.; Shah, A.N.; Shahzad, B. Exogenously applied methyl jasmonate improves the drought tolerance in wheat imposed at early and late developmental stages. Acta Physiol. Plant. 2016, 38, 25. [CrossRef]

29. Yoshida, C.H.P.; Pacheco, A.C.; Lapaz, A.M.; Gorni, P.H.; Vítolo, H.F.; Bertoli, S.C. Methyl jasmonate modulation reduces photosynthesis and induces synthesis of phenolic compounds in sweet potatoes subjected to drought. Bragantia 2020, 79, 319-334. [CrossRef]

30. Siboza, X.I.; Bertling, I. The effects of methyl jasmonate and salicylic acid on suppressing the production of reactive oxygen species and increasing chilling tolerance in 'Eureka' lemon [Citrus limon (L.) Burm F]. J. Hortic. Sci. Biotechnol. 2013, 88, 269-276. [CrossRef]

31. Ahmmed, S.; Jahiruddin, M.; Razia, S.; Begum, R.A.; Biswas, J.C.; Rahman, A.S.M.M. Fertilizer Recommendation Guide-2018; Bangladesh Agricultural Research Council (BARC): Dhaka, Bangladesh, 2018.

32. Ogbaga, C.C.; Stepien, P.; Johnson, G.N. Sorghum (Sorghum bicolor) varieties adopt strongly contrasting strategies in response to drought. Physiol. Plant. 2014, 152, 389-401. [CrossRef]

33. Arnon, D. Copper enzymes isolated chloroplasts, polyphenol oxidase in Beta Vulgaris. Plant. Physiol. 1949, 24, 1-15. [CrossRef]

34. Fischer, R.A.; Rees, D.; Sayre, K.D.; Lu, Z.M.; Condon, A.G.; Saavedra, L.A. Wheat yield progress associated with higher stomatal conductance and photosynthetic rate, and cooler canopies. Crop. Sci. 1998, 38, 1467-1475. [CrossRef]

35. Shivakrishna, P.; Reddy, K.A.; Rao, D.M. Effect of PEG-6000 imposed drought stress on RNA content, relative water content (RWC), and chlorophyll content in peanut leaves and roots. Saudi J. Biol. Sci. 2018, 25, 285-289.

36. Sairam, R.K.; Deshmukh, P.S.; Shukla, D.S. Tolerance of drought and temperature stress in relation to increased antioxidant enzyme activity in wheat. J. Agron. Crop. Sci. 1997, 178, 171-178. [CrossRef]

37. Bates, L.S.; Waldren, R.P.; Teari, D. Rapid determination of free proline for water stress studies. Plant. Soil 1973, 39, 205-207. [CrossRef]

38. Elstner, E.F.; Heupel, A. Inhibition of nitrite formation from hydroxylammoniumchloride: A simple assay for superoxide dismutase. Anal. Biochem. 1976, 70, 616-620. [CrossRef]

39. Yang, S.-H.; Wang, L.-J.; Li, S.-H. Ultraviolet-B irradiation-induced freezing tolerance in relation to antioxidant system in winter wheat (Triticum aestivum L.) leaves. Env. Exp. Bot. 2007, 60, 300-307. [CrossRef]

40. Heath, R.L.; Packer, L. Photoperoxidation in isolated chloroplast: I. Kinetics and stoichiometry of fatty acid peroxidation. Arch. Biochem. Biophys. 1968, 125, 189-198. [CrossRef]

41. Mohi-Ud-Din, M.; Siddiqui, N.; Rohman, M.; Jagadish, S.V.K.; Ahmed, J.U.; Hassan, M.M.; Hossain, A.; Islam, T. Physiological and biochemical dissection reveals a trade-off between antioxidant capacity and heat tolerance in bread wheat (Triticum aestivum L.). Antioxidants 2021, 10, 351. [CrossRef]

42. Bradford, M.M. A rapid and susceptible method for the quantitation of microgram quantities of protein utilizing the principle of protein-dye binding. Anal. Biochem. 1976, 72, 248-254. [CrossRef]

43. Doderer, A.; Kokkelink, I.; van der Veen, S.; Valk, B.; Schram, A.; Douma, A. Purification and characterization of two lipoxygenase isoenzymes from germinating barley. Biochim. Biophys. Acta 1992, 112, 97-104. [CrossRef]

44. Spitz, D.R.; Oberley, L.W. An assay for superoxide dismutase activity in mammalian tissue homogenates. Anal. Biochem. 1989, 179, 8-18. [CrossRef]

45. Noctor, G.; Mhamdi, A.; Foyer, C.H. Oxidative stress and antioxidative systems: Recipes for successful data collection and interpretation. Plant Cell Environ. 2016, 39, 1140-1160. [CrossRef] [PubMed]

46. Castillo, F.I.; Penel, I.; Greppin, H. Peroxidase release induced by ozone in sedum album leaves. Plant. Physiol. 1984, 74, 846-851. [CrossRef] [PubMed]

47. Elia, A.C.; Galarini, R.; Taticchi, M.I.; Dörr, A.J.; Mantilacci, L. Antioxidant responses and bioaccumulation in Ictalurus melas under mercury exposure. Ecotoxicol. Env. Saf. 2003, 55, 162-167. [CrossRef]

48. Hossain, M.Z.; Hossain, M.D.; Fujita, M. Induction of pumpkin glutathione S-transferase by different stresses and its possible mechanisms. Biol. Plant. 2006, 50, 210-218. [CrossRef]

49. Kolde, R. Pheatmap: Pretty Heatmaps, Version 1.0.12. rdrr.io 2019. Available online: https://rdrr.io/cran/pheatmap/ (accessed on 29 May 2021).

50. Lê, S.; Josse, J.; Husson, F. FactoMineR: An R package for multivariate analysis. J. Stat. Softw. 2008, 25, 1-18. [CrossRef] 
51. Wickham, H. Ggplot2: Elegant Graphics for Data Analysis; Springer: New York, NY, USA, 2016.

52. Pardossi, A.; Incrocci., L.; Incrocci, G.; Malorgio, F.; Battista, P.; Bacci, L.; Rapi, B.; Marzialetti, P.; Hemming, J.; Balendonck, J. Root zone sensors for irrigation management in intensive agriculture. Sensors 2009, 9, 2809-2835. [CrossRef]

53. Weng, E.; Luo, Y. Soil hydrological properties regulate grassland ecosystem responses to multifactor global change: A modeling analysis. J. Geophys. Res. 2008, 113, G03003. [CrossRef]

54. Anjum, N.A.; Umar, S.; Ahmad, A. Oxidative Stress in Plant: Causes, Consequences and Tolerance; IK International Publishing House Pvt Ltd.: New Delhi, India, 2012.

55. Huang, H.; Liu, B.; Liu, L.; Song, S. Jasmonate action in plant growth and development. J. Exp. Bot. 2017, 68, 1349-1359. [CrossRef]

56. Abbaspour, H.; Saeidi-Sar, S.; Afshari, H. Improving drought tolerance of Pistacia vera L. seedlings by arbuscular mycorrhiza under greenhouse conditions. J. Med. Plant. Res. 2011, 5, 7065-7072. [CrossRef]

57. Pandey, H.C.; Baig, M.J.; Bhatt, R.K. Effect of moisture stress on chlorophyll accumulation and nitrate reductase activity at vegetative and flowering stage in Avena species. Agric. Sci. Res. J. 2012, 2, 111-118.

58. Dalal, V.K.; Tripathy, B.C. Water-stress induced downsizing of light-harvesting antenna complex protects developing rice seedlings from photo-oxidative damage. Sci. Rep. 2018, 8, 5955. [CrossRef]

59. Mohamed, H.I.; Latif, H.H. Improvement of drought tolerance of soybean plants by using methyl jasmonate. Physiol. Mol. Biol. Plants 2017, 23, 545-556. [CrossRef] [PubMed]

60. Razmi, N.; Ebadi, A.; Daneshian, J.; Jahanbakhsh, S. Salicylic acid induced changes on antioxidant capacity, pigments and grain yield of soybean genotypes in water deficit condition. J. Plant. Interact. 2017, 12, 457-464. [CrossRef]

61. Royo, C.; Villegas, D.; Del Moral, L.G.; Elhani, S.; Aparicio, N.; Rharrabti, Y.; Araus, J.L. Comparative performance of carbon isotope discrimination and canopy temperature depression as predictors of genotype differences in durum wheat yield in Spain. Aust. J. Agric. Res. 2002, 53, 561-569. [CrossRef]

62. Ahmed, H.G.M.-D.; Zeng, Y.; Yang, X.; Anwaar, H.A.; Mansha, M.Z.; Hanif, C.M.S.; Ikram, K.; Ullah, A.; Alghanem, S.M.S. Conferring drought-tolerant wheat genotypes through morpho-physiological and chlorophyll indices at seedling stage. Saudi J. Biol. Sci. 2020, 27, 2116-2123. [CrossRef]

63. Mohi-Ud-Din, M.; Hossain, M.A.; Rohman, M.M.; Uddin, M.N.; Haque, M.S.; Ahmed, J.U.; Hossain, A.; Hassan, M.M.; Mostofa, M.G. Multivariate analysis of morpho-physiological traits reveals differential drought tolerance potential of bread wheat genotypes at the seedling stage. Plants 2021, 10, 879. [CrossRef]

64. Balota, M.; Payne, W.A.; Evett, S.R.; Peters, T.R. Morphological and physiological traits associated with canopy temperature depression in three closely related wheat lines. Crop. Sci. 2008, 48, 1897-1910. [CrossRef]

65. Kadioglu, A.; Saruhan, N.; Sağlam, A.; Terzi, R.; Acet, T. Exogenous salicylic acid alleviates effects of long-term drought stress and delays leaf rolling by inducing antioxidant system. Plant. Growth Regul. 2011, 64, 27-37. [CrossRef]

66. Ashraf, M.; Foolad, M.R. Roles of glycinebetaine and proline in improving plant abiotic resistance. Env. Exp. Bot. 2007, 59, 206-216. [CrossRef]

67. Rampino, P.; Pataleo, S.; Gerardi, C.; Mita, G.; Perrotta, C. Drought stress response in wheat: Physiological and molecular analysis of resistant and sensitive genotypes. Plant. Cell Env. 2006, 29, 2143-2152. [CrossRef]

68. Wang, G.P.; Zhang, X.Y.; Li, F.; Luo, Y.; Wang, W. Overaccumulation of glycine betaine enhances tolerance to drought and heat stress in wheat leaves in the protection of photosynthesis. Photosynthetica 2010, 48, 117-126. [CrossRef]

69. Dixon, D.P.; Skipsey, M.; Edwards, R. Roles for glutathione transferases in plant secondary metabolism. Phytochemistry 2010, 71, 338-350. [CrossRef] [PubMed]

70. Hasanuzzaman, M.; Fujita, M. Selenium pretreatment upregulates the antioxidant defense and methylglyoxal detoxification system and confers enhanced tolerance to drought stress in rapeseed seedlings. Biol. Trace Elem. Res. 2011, 143, 1758-1776. [CrossRef] [PubMed]

71. Nahar, K.; Hasanuzzaman, M.; Alam, M.M.; Fujita, M. Glutathione-induced drought stress tolerance in mung bean: Coordinated roles of the antioxidant defence and methylglyoxal detoxification systems. Aob Plants 2015, 7, plv069. [CrossRef]

72. Nafie, E.; Hathout, T.; Mokadem, A.S.A. Jasmonic acid elicits oxidative defense and detoxification systems in Cucumis melo L. cells. Braz. J. Plant. Physiol. 2011, 23, 161-174. [CrossRef] 